\title{
A fresh start for European science
}

\section{Barry Holland}

\author{
Instead of becoming embroiled in bureaucracy and the misplaced support of 'network' projects, the European \\ Commission could provide an exciting, long-term science policy.
}

LET me declare my interest immediately. I strongly support the concept of a single European scientific community - who could not? - and I believe that the European Commission in Brussels can and must play a vital role in promoting this concept. Indeed, I have experienced and benefited from the Commission's efforts in my own research. But after more than 10 years of sponsoring projects, rather than individuals, the Commission's policy needs to be assessed.

This question is particularly crucial at a time when the European Union is floundering in its attempts to maintain the "European ideal". An exciting, long-term European science policy would provide the perfect opportunity for renewing the momentum towards greater integration. Rationalization of higher-education policy and the unrestricted freedom of movement of scientists throughout Europe are two areas that the Commission is in a position to promote with great effect.

In advocating such a policy, I have to say that Brussels, for all the undoubted dedication of the people working there, has been pursuing a science policy that it is ill-suited to carry out. I believe that the Commission should largely jettison its efforts to identify "winning projects", whether fundamental or applied, and should instead promote the concept of a sustained European science policy. The direct funding of projects should be left to national agencies, which are far better equipped to assess fundamental and applied science through hands-on experience and informed peer review.

The scientific arm of the Commission suffers the handicap of having no true roots in academic or industrial communities across Europe. As such it cannot be in tune with the pressing needs of scientific research or its commercial exploitation. Yet the Commission's scientific administrators develop frequent initiatives, no doubt with the highest of motives, in selected areas of basic or applied science, without the knowledge and experience of national agencies, which (quite rightly) are dominated by active scientists with close links with local academic and industrial sectors.

\section{Collaborative bureaucracy}

European Union initiatives have the laudable aim of promoting collaborations between member states, but how successful have these been? The Commission has no way of taking the pulse of activity on the ground, or to anticipate the natural collaborations that are being held back for lack of funding or opportunity. Rather, proposals are tossed to the scientific community in the expectation that collaborations will automatically follow, which the Commission has divined as "good". The retort may be that scientists are only too happy to scramble for these delights well, yes, we are. Scientists, particularly impoverished scientists, have become adept, chameleon-like, in adjusting to the requirements of the most specific projects imaginable. But what a degree of contortion this can necessitate - and what pain, effort and time can be taken to produce in some cases quite phoney collaborations! And this is the easy part. Unlike most national funding agencies with which I am familiar, access to European funding is overwhelmingly bureaucratic: contracts brim with legalistic and semi-commercial detail; cash takes an inordinate amount of time to arrive; and there is no understanding of the realities of recruiting staff and the complexities of managing modern scientific groups.

In my opinion, the unquestioned talents and vision of the Commission could be far more effectively used to promote the greater mobility of European scientists, which would lead to better collaborations than have so far been achieved. This should include greater mobility for graduate students, postdocs and for established scientists as individuais, not linked to cumbersome networks. Movement of graduate students between countries to complete a $\mathrm{PhD}$ is essentially zero. Movement of postdocs has improved, but demand greatly exceeds the available funding. Regular programmes to support short-term movement of established scientists are rare, and permanent migration is still greatly inhibited by nontransferable pension schemes, bureaucracy and national idiosyncracies.

I propose that the Commission devotes the bulk of its funding for the support of PhD students to study in member states other than their own; for postdoctoral fellowships; for short- and long-term visits for established scientists; and for greater support for multinational workshops and symposia. The procedures, while remaining accountable, must be greatly streamlined. Most important, such a programme must be sustained over a decade or more if it is to have real impact (why must
Brussels chop and change its initiatives so frequently?).

The Commission must back this policy with strong leadership to rationalize PhD training and career development throughout member states. The objective would be to produce more flexible and, above all, more rapid career progression to independent status for young scientists. The potential of talented individuals is being held back in many European countries by insufficient support or by suffocation from outdated academic hierarchies, which block mobility even within the national framework. Different member states, no doubt for different reasons, appear unable to deal with the key issues of graduate training or to appreciate the need for attractive, effective career structures. The Commission is in an ideal position to generate ideas and leadership.

\section{Sustained effort}

In terms of graduate training, the Commission could draw up guidelines for $\mathrm{PhD}$ training - putting its weight behind, for example, the growing consensus for a fully funded master's degree followed by a further 3 years' research training. These guidelines could remove many anomalies, such as costs incurred by non-nationals studying for a $\mathrm{PhD}$ (essentially nothing in France compared with several thousand pounds in the United Kingdom), guaranteed length of time for funding (3 years in the United Kingdom but only 2 years in France) and so on. Similarly, the Commission should look at career development: in some countries postdoctoral funding is essentially non-existent, resulting in enormous bottlenecks in people's careers.

The essence of my plea is that we desperately need a much greater concentration of effort on the training of young scientists and the removal of barriers, both physical and psychological, to easy movement for training and to subsequent career development. This must be a sustained programme with a minimum of bureaucracy. In my view the Commission, free of national political baggage, is in a far better position to implement such a policy than individual member states. National agencies, on the other hand, are best able to formulate policies for the stimulation of specific areas of science.

1. Barry Holland is at the Institut de Genetique et Microbiologie, Bâtiment 409, Université de Paris XI, 91405 Orsay, France. 